\title{
TRENDS IN DEVELOPMENT OF PHYSICAL ABILITY OF STUDENTS WITHOUT PRIOR ATHLETIC TRAINING
}

\author{
Rihards Parandjuks \\ University of Latvia, Latvia
}

\begin{abstract}
The research aims to focus on the fitness of students who have not undertaken athletic training. Studies in this field have not been extensive as attention has been focused on athletes representing universities. However, the number of athletes in a university is significantly lower than that of students without prior athletic training - only about $10 \%$ of all students are athletes. This research shows that notable progress in physical ability can be achieved among students who have not yet undertaken physical training. Methodology: physical testing of 30 students after eight weeks of a training program. The obtained results were processed and analyzed with the Windows Exel program.
\end{abstract}

Keywords: Fitness, sport, student sport, explosive straight, endurance.

\section{Introduction}

Research problem - respondents in physical fitness researches mostly are athletes. However, their potential progress may differ significantly from that of respondents without previous physical training. This research's target group includes students from general physical fitness groups of the University of Latvia Sports Center, aged 19 to 27. The number of enrolled participants is 30. Initially, students' overall physical fitness and physical ability were determined with the following development of a fitness plan and workouts. At the end of the training program, students were asked to repeat exercises to evaluate their physical abilities. Data were analyzed using Windows Excel, and conclusions were made based on data analysis. This research is connected to the notion of dual careers, yet views it from a different perspective, because students must combine regular training with general health in parallel with their studies. Insufficient attention has been given to students that perform physical activities for recreational purposes. The author of this research believes that a relatively good performance is attainable even if an individual has not previously undertaken extra physical activity. This process facilitates multiple positive tendencies that 
include better and more controlled functioning of the body, improved outlook on a healthy lifestyle, increased self-confidence, and potentially added motivation to the academic study process (Moeijes, Busschbac, 2019). A similar view has been expressed by other sport researchers (Simona, Mirecea, 2015).

Previous involvement of sports participants had been in secondary schools without any extra workouts outside of the mandatory curriculum. Studies at university mark a new beginning and involve searching for new hobbies, one of which is sports that encompass various activities. Participants began the academic year 2019/2020 and simultaneously started attending general physical fitness workouts organized by the University of Latvia's Sports Center. Their main goal was to improve body functionality.

The development of physical ability was focused on two aspects. One of these was explosive strength. It forms the basis of many different physical activities as it ensures rapid movement in the shortest amount of time possible. Such movements are an integral part of basketball, football, volleyball, and other sports. Exercises targeted at developing explosive strength are based on anaerobic exercise (Santos, 2008). A Chinese researcher also shared a similar view (Zhang, 2012).

There is a variety of ways and training programs that develop rapidly to improve explosive strength. Researchers in Slovakia studied an eight-week training program that involved jumping exercises and squats in improving explosive strength (Vadeika, Longova, 2016). Both activities are crucial for developing explosive strength (Bruce-Low, Smith, 2007). However, this research included participants without prior physical training. Therefore it was necessary to evaluate potential exercises. Participants were asked to perform different squats variations, which were performed using only the participants' body weight without extra weights, i.e., the use of barbells. This choice was made based on the level of physical preparedness of participants. In order to perform squats or similar exercises using additional weight, there is a need for a certain level of physical preparedness and development of core muscles.

Due to the reason, as mentioned above, of lack of developed core muscles, specific exercises could not be included in assessing strength abilities. One of these is maximum strength. The standard exercise for assessment is one repetition of a weighted squat done with a maximum weight. This exercise can only be performed by athletes or people who have undergone training for such exercises.

The other aspect of physical ability evaluated in this research was endurance. It is part of many different sports. Typical examples include rowing (strength endurance), middle and long-distance running, swimming, etc. Each of these examples is specific and differ from the others. 
The author of this research chose to evaluate participants using running as the form of exercise, setting the goal at $1000 \mathrm{~m}$. This choice was based on the available infrastructure and the overall ability of participants to complete the distance.

Possible ways and methods to improve endurance are variable. Daily exercise allows the development of endurance for both high and lowintensity activities. Additional exercises were also planned to develop endurance while concurrently performing running workouts successfully. Authors in China, who have researched an eight-week training program focusing on improving endurance, found that additional exercises played an equal role in running workouts in developing endurance. Researchers had implemented holding the plank position and other multifunctional exercises to improve coordination and agility (Hung, 2019; Everan, Cecen, 2019). This approach indicates that any athlete or anyone, who exercises as a hobby, should include different exercises in their routine without straining only certain muscle groups. The framework of this research was based on this approach (Wall, 2014).

The training program was designed in conformity with other authors and fitness instructors' experience aiming to develop physical ability. One of the studies used was by Portuguese authors focused on explosive strength. This study's premise was different from that of the author, as its target population was basketball players in the age group of 14 to 15 years. However, the study employed jumping exercises denoted as plyometrics (Santos, 2008). Other exercises were also implemented in that study, i.e., using medicine balls. Since this research focuses on students without prior training, exercises included in the program cannot be too specific or require professional skills.

Another study analyzed the correlation of volleyball with parameters of explosive strength. It was based on standing high jump that is an integral part of volleyball in elements such as serves, blocks, or attacks (Simona, Mirecea, 2015). Thus, explosive strength can be improved in team sports. A downside is the lack of skills to correctly perform the necessary elements and difficulties assessing the movements, i.e., counting the number of jumps during a volleyball match.

Endurance was the other ability to be evaluated; therefore, exercises targeted at improving it were part of the training program. Endurance was assessed with a $1000 \mathrm{~m}$ run, although the training process was not focused solely on running. Participants improved their endurance by performing runs at a steady pace of a maximum of 30 minutes per workout session. These workouts are classified as aerobic exercise.

Numerous studies are highlighting the importance of endurance training. Nevertheless, the primary subject matter concerns an improvement in 
endurance for professional athletes, who run distances of at least $15 \mathrm{~km}$ per day as a part of their training process. Studies from Spain have investigated methods for improving endurance. A long-term study was conducted to analyze the effects of different running workouts on endurance among professional athletes. Various paces were compared, such as repetitions of the same distance or repeated runs of differing distances and run with longer and shorter breaks in between. Another running workout included a steady pace, where an athlete was required to run a set distance at a slower pace (Casado, Hanley, 2019; Bruce-Low, Smith, 2007). Data showed that running at a steady pace had a relatively good effect on endurance, yet it was neither the best nor worst in improving endurance. Running at a steady pace has a better effect on heart rate and has less impact on joints, i.e., knees, heels, and back. Thus a decision was made to implement running workouts at a relatively slow, steady pace. The data were collected by a general fitness trainer, who is also a research author. The research participants were informed about the planned process, and relevant tests were performed with better quality and maximum effort.

\section{Research process}

In line with the research of other authors, the period of training was eight weeks. The research was conducted from 1 October 2019 until 19 November 2019. Method used - analysis of the results within eight weeks with tests in the start and final stage. The obtained results were processed and analyzed by the Windows Exel program. The results obtained indicate the progress shown in the relevant physical properties.

Initial exercises that were performed were aimed to evaluate explosive strength and included standing long jump, highest standing jump, and 30-meter sprint. Endurance testing included a 1000 meter run at the fastest pace. Participants performed these tests after one month of training. Following this assessment, participants underwent more intensive training three times a week. Two out of three workout sessions were with a fitness instructor (author). The training program was developed to improve participants' explosive strength and endurance within the given period and emphasize the need for general physical fitness improvements, such as strengthening the core, intrinsic muscles, coordination, and agility (See Table 1). 
Table 1. Exercises and running workouts included in one week of training

\begin{tabular}{|l|l|l|}
\hline \multicolumn{1}{|c|}{ Exercises } & \multicolumn{1}{|c|}{ Sets and repetitions } & \multicolumn{1}{c|}{ Instructions } \\
\hline 1. Standing long jump & $\begin{array}{l}10 \text { repetitions, } \\
9 \text { sets (3 sets in each } \\
\text { workout) }\end{array}$ & $\begin{array}{l}\text { The position of the back is } \\
\text { crucial during this exercise, } \\
\text { including landing }\end{array}$ \\
\hline $\begin{array}{l}\text { 2. Highest standing } \\
\text { jump }\end{array}$ & $\begin{array}{l}10 \text { repetitions, } \\
\text { 9 sets (3 sets in each } \\
\text { workout) }\end{array}$ & $\begin{array}{l}\text { Legs must be moved to } \\
\text { the front during the jump at } \\
\text { a 90-degree angle }\end{array}$ \\
\hline 3. Squats & $\begin{array}{l}\text { 20 repetitions, } \\
\text { 6 sets (3 sets in two } \\
\text { workouts) }\end{array}$ & $\begin{array}{l}\text { During squats, feet must be } \\
\text { fully planted on to the ground. } \\
\text { The movement starts with } \\
\text { the hinge at the hips }\end{array}$ \\
\hline 4. Sprint & $\begin{array}{l}\text { Distance from 20 m up } \\
\text { to } 100 \text { m. 4-8 sprints } \\
\text { (done within two } \\
\text { workout sessions) }\end{array}$ & $\begin{array}{l}\text { Focus on the first steps should } \\
\text { be wide and based on explosive } \\
\text { strength. Maximum pace }\end{array}$ \\
\hline $\begin{array}{l}\text { 5. Distance running } \\
\text { 6. Various core } \\
\text { exercises }\end{array}$ & $\begin{array}{l}\text { Steady pace run for } \\
\text { 80 minutes (total } \\
\text { duration completed in } \\
\text { three workouts) }\end{array}$ & $\begin{array}{l}\text { Two workouts per week include } \\
\text { 15 minutes of running and one } \\
\text { workout with 30 minutes of } \\
\text { running }\end{array}$ \\
\hline $\begin{array}{l}\text { 30 minutes in each } \\
\text { session }\end{array}$ & $\begin{array}{l}\text { Exercises targeting back and } \\
\text { abdominal muscles, variations } \\
\text { of plank position }\end{array}$ \\
\hline
\end{tabular}

The respondents' results presented in the respective physical exercises sowed that the chosen training methods are advanced (See Figure 1, Figure 2, and Table 2).

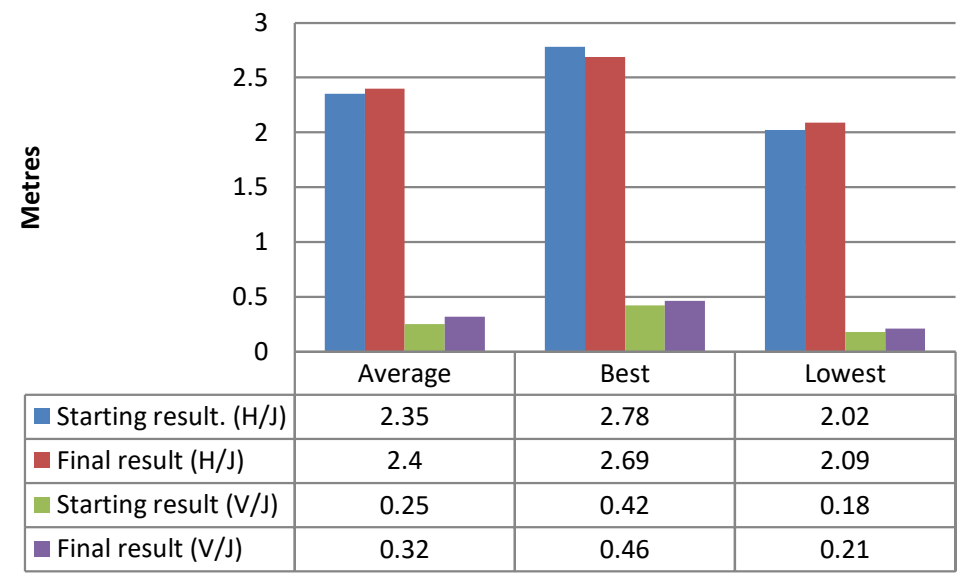

Figure 1. Results of explosive power in jumping exercises 
Results obtained from the assessment of explosive strength points at several trends. One of them is that progress is not significant. For example, the average result of standing long jump at the beginning of the training program was $2.35 \mathrm{~m}$. After two months of intensive training, the increase was within $5 \mathrm{~cm}$ from initial results indicating insignificant changes. Relatively better progress can be observed for the weakest result in the group with an initial result of $2.02 \mathrm{~m}$ and an improved result of $2.09 \mathrm{~m}$ $(+7 \mathrm{~cm})$. Unfortunately, the opposite effect was noted for the group's initial best result as it showed a $9 \mathrm{~cm}$ decline from $2.78 \mathrm{~m}$ at the outset of training and $2.69 \mathrm{~cm}$ at the end of the training program. Better results were obtained in the standing high jump. In the case of this exercise, each extra centimeter requires more effort. The group's average result was fixed at $0.25 \mathrm{~m}$, whereas the result was $0.32 \mathrm{~m}$; therefore, an improvement of $7 \mathrm{~cm}$ can be viewed as significant. Progress was also noted for the group's weakest and best results; however, both were lower than the group average, 4 and $3 \mathrm{~cm}$.

Differences in progress for both exercises can have various reasons. Theoretically, progression curves should correlate as both exercises are based on explosive strength. Nevertheless, results for standing high jump were distinctly higher, if its progression curve is analyzed separately. The technique of the specific exercise can explain it. It may be the case that participants performed the exercise incorrectly at the initial evaluation, thus failing to reach their maximum potential. However, these nuances were corrected at the end of the research yielding valuable results. The main principle of sport pedagogy, which was infused during the exercises, performed extremely fast and with full effort.

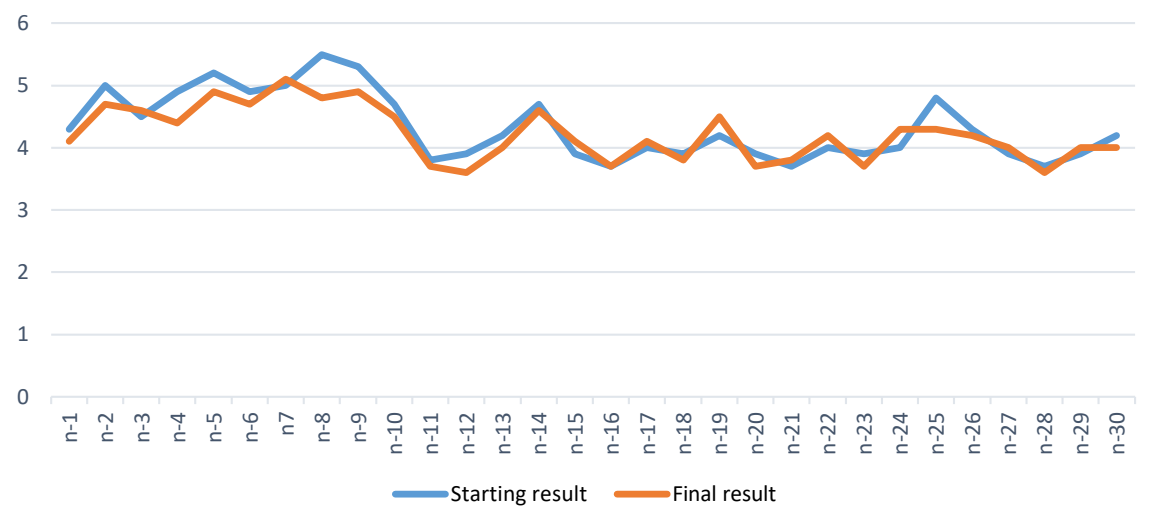

Figure 2. Results of 30 metres sprint 
The third exercise included in this research was a sprint at maximum pace, which is also based on explosive strength. The time control was done for a 30-meter distance, with the participant building speed up already before initiating the time control. The average result at the outset of research was $4.16 \mathrm{~s}$. At the end of the research period, it was $4.04 \mathrm{~s}$. Therefore the overall improvement was by $0.12 \mathrm{~s}$. This improvement can be viewed as satisfactory for a short distance sprint. Analysis of chart No. 2 distribution of both curves should be noted. The task of participants was to complete the distance in the shortest amount of time. Consequently, the curves should be closer to zero for the best results. Most participants improved their results, which can be seen in figure 2, namely, the red curve is lower than the blue curve. In some instances, curves cross in the opposite direction, meaning that a participant had a worse result at the end of the training program, e.g., n-26.

Analysis of results for explosive strength leads to a conclusion that results show differences among exercises. Curves for standing high jump and $30 \mathrm{~m}$ sprint show progress, whereas standing long jump results are not satisfactory.

Endurance was the other physical ability that was evaluated with a 1000 meter run at the fastest pace. The results are displayed in table No 2 .

Data indicated that 7 participants showed a decline in their result after two months of intensive training, whereas 23 participants improved their results. Substantial progress was noted for participants $n-7$ and n-11 with a 6-second improvement in their result. The rest of the respondents had average progress of 2-3 seconds, which in the framework of a 1000 meter run, can be defined as steady considering the general fitness of participants.

Table 2. Results on 1000 metres running

\begin{tabular}{|c|c|c|c|c|c|c|c|c|c|c|c|c|c|c|c|}
\hline $\begin{array}{l}\text { Partici- } \\
\text { pants No. }\end{array}$ & 1. & 2. & 3. & 4. & 5. & 6. & 7. & 8. & 9. & 10. & 11. & 12. & 13. & 14. & 15. \\
\hline Start result & $4: 23,4$ & $5: 05,4$ & $5: 12,5$ & $4: 56,2$ & $5: 23,5$ & $5: 46,4$ & $4: 57,3$ & $5: 11,4$ & $3: 56,4$ & $3,30,1$ & $4: 54,5$ & $4: 30,2$ & $4: 21,2$ & $3: 40,3$ & $4: 00,2$ \\
\hline Final result & $4: 19,3$ & $4: 59,8$ & $5: 13,1$ & $4: 50,0$ & $5,21,1$ & $5: 45,4$ & $4: 51,3$ & $5: 08,4$ & $3: 49,6$ & $3: 28,4$ & $4: 48,2$ & $4: 32,4$ & $4: 17,4$ & $3: 36,5$ & $3: 56,4$ \\
\hline $\begin{array}{l}\text { Respondent } \\
\text { No. }\end{array}$ & 16. & 17. & 18. & 19. & 20. & 21. & 22. & 23. & 24. & 25. & 26. & 27. & 28. & 29. & 30. \\
\hline Start result & $3: 44,5$ & $4: 02,4$ & $3: 11,5$ & $4: 00,2$ & $3: 33,5$ & $3: 56,4$ & $4: 50,4$ & $4: 22,4$ & $5: 00,3$ & $3: 56,1$ & $4: 22,4$ & $5: 03,3$ & $4: 33,2$ & $3: 31,3$ & $4: 03,2$ \\
\hline Final result & $3: 45,0$ & $3: 57,0$ & $3: 09,9$ & $3: 55,5$ & $3: 34,0$ & $3: 50,5$ & $4: 45,0$ & $4: 19,0$ & $4: 54,6$ & $3: 57,0$ & $4: 24,0$ & $5: 01,4$ & $4: 34,1$ & $3: 27,5$ & $4: 02,1$ \\
\hline
\end{tabular}


There may be various reasons why some participants did not improve their results. One of them might be that the initial result was excellent, i.e., n-16 had a result of 3:44,5 and at the end of the program showed a decline of $0.5 \mathrm{~s}$. The initial result for someone without prior physical training is relatively high. Therefore it is more challenging to improve the result. Another affecting factor could be a potential overload, which can hamper the body's ability to perform at the highest level.

\section{Discussion}

Results indicate different levels of progress. Analysis of studies by other authors reveals that multiple factors can impact the performance of participants. One of them is the process of rehabilitation. Researchers from the Czech Republic (Macakowa, Burianova, 2007) studied the effects of spa rehabilitation on children's physical and emotional state. Various additional factors must be taken into account to make the result as objective as possible. Results showed a significant difference in performance before and after rehabilitation. The connection between both of these research lies in the fact that participants were exposed to other stressors. Various daily factors, such as studies and work, which affects their ability to recover. Also, access to rehabilitation can differ; thus, participants are not subject to similar conditions.

Analysis of the chosen training program reveals that it served its purpose. Most participants improved their physical ability. Nevertheless, many studies employ different training programs, both in terms of activity levels and recovery. For example, a study on football referees' general physical fitness used a 40-meter sprint with a break of 1 minute to improve explosive strength. It had to be done for four repetitions and within a given time limit (Monea, Sabau, 2019; Santos, 2008). An opposite opinion was presented by an Australian researcher demonstrating another method for improving explosive strength. They were running at maximum pace for more than 15 seconds, which also facilitated speed endurance development. As a result, an athlete completed a distance of around 200 meters per run, which is substantially different from routine distances used to improve explosive strength (Ross, Leveritt, 2001).

Results of endurance tests indicate relatively good progress. However, due to participants not being professional athletes, their training process was adapted to their circumstances. During a week, participants completed 80 minutes of running at a steady pace equal to about $12-14 \mathrm{~km}$. Several sports researchers have discussed the necessary running distance for professional runners. For example, young adults aged 18-19 should run at least $110 \mathrm{~km}$ per week (Tjelta, 2016). Another study involved participants 
similar to this research, amateur runners, that have completed a marathon. In this study, participants ran 30-60 km per week (Rassmusen, 2013). These studies are based on developing specific physical abilities; therefore, intensity can be higher. This research focused on improving both explosive strength and endurance; moreover, its participants were students without prior physical training. As a result, developing a training program required careful assessment of the training load as an overload can lead to a decline in physical ability and negatively affect health. A similar study focusing on the general public included exercises comparable to this research found that progress in explosive strength, endurance, and strength endurance was made, and it had a positive effect on general health (Nazzer, Ilyas, 2016).

\section{Conclusions}

Data show that the initial notion of potential to progress relatively quickly can be confirmed. It is reasserted by several exercises, i.e., standing high jump, 30-meter sprint, and 1000 meter run. Progress in standing long jump was low; therefore, these results cannot be viewed as satisfactory. The chosen training program was based on evaluating several factors students' abilities, schedule, and potential achievement.

Analysis of data and studies by other authors indicate that the level of progress is affected by numerous factors. The most important are the following:

- Ability to recover sufficiently to ensure full engagement in the research process and best performance results. In case of interference in this process, such as high workloads in studies or work can have a negative impact on physical performance;

- Training program and methods. Development of physical body functions can be likened to art; namely, one size does not fit all; each target group needs an individualized approach. Therefore, potentially other exercises could have been employed in the training program. Although progress was satisfactory, the outcome was expected to be better. Eight weeks of training was the right choice in line with several sports researchers' opinions, yet the chosen exercises, a number of repetitions and sets, could still be discussed as this differed in structure from what has been used by other authors. Basic exercises were similar among different studies, with a few differences in certain activities. Therefore these basic exercises were also part of this research;

- Physical fitness of participants. Although participants enrolled in this research were young adults (19-27 years of age), their physical fitness levels were variable. A common factor was that they did not perform additional physical exercises or activities daily. Progress is also affected 
by genetic factors and the capability to learn new skills and adapt to specific movements.

Progress in both endurance and explosive strength was significant; however, initial expectations were higher. Most studies focus on professional athletes and their progress; consequently, available resources investigating physical fitness and the ability of non-athletes are scarce.

The main conclusions are that both endurance and explosive strength can be improved over a period of 8 weeks in people without prior physical training. The development of a suitable training program and adherence is crucial to success. The training program developed as part of this research confirms that the program exercises are justified and ensure progress.

\section{References}

Bruce-Low, S., \& Smith, D. (2007). Explosive Exercises In Sports Training: A Critical Review. Journal of Exercise Physiology, 10(1).

Casado, S., \& Hanley, A., \& Santos-Concejero, J., \& Ruiz, L. M. (2019). World-Class Long-Distance Running Performances Are Best Predicted by Volume of Easy Runs and Deliberate Practice of Short-Interval and Tempo Runs. The Journal of Streight and Conditioning Research, 10(15).

Everan, A. K., \& Cecen, I. A. (2019). The Effect of a 8 Week-Explosive Power Training on Some Performance Parameters of Students who Studying in Sports High School. Published by Canadian Center of Science and Education. ISSN 1925-4741.

Hung., C. K. (2019). Effects Of 8-Week Core Training On Core Endurance And Running Economy. Journal PLoS One, 14(3).

Mackova, Z., \& Burianova, K. (2007). The Influence Of One Month Complex Spa Therapy On The Muscular Fitness And General Physical Fitness Of Obese Children. Acta Universitatis Palackianae Olomucensis. Gymnica, 37(4), 99-106.

Moeijes, J. \& Busschbac, J. T., \& Twisk, J. W. R. (2019). Sports Participation And Health-Related Quality Of Life: A Longitudinal Observational Study In Children. Quality of Life Research, 28, 2453-2469.

Monea, D., \& Sabau, E., \& Niculestu, G., \& Lupu, E. (2019). Football Referees' Physical Fitness. The European Proceedings of Social \& Behavioural Sciences. 2357-1330.

Nazeer, T. M., \& Ilyas, M. (2016). Impact Of Fitness Awareness On Physical Fitness And Exercise Activities Of Visitors In Public Parks. Sci.Int.(Lahore), 28(5), 99-102.

Rassmusen, S. (2013). Weekly Running Volume And Risk Of Running-Related Injuries Among Marathon Runners. Int J Sports Phys Ther., 8(2), 111-20.

Ross, A., \& Leveritt, M., \& Riek, S. (2001). Neural Influences on Sprint Running. Sport Med., 31(6), 409-425.

Santos, E. J. A. (2008). Effects of Complex Training on Explosive Strength in Adolescent Male Basketball Players. Journal of Strength and Conditioning Research, 22(3), 903-909.

Simona, D. T., \& Mirecea, N., Florin, T. (2015). The Progress Of The Volleyball Game By Efficency Of II-Line Attack. Procedia - Social and Behavioral Sciences. 1374-1379 
Tjelta, I. L. (2016). The Training Of International Level Distance Runners. Leif Inge Tjelta, Department of Education and Sports Science, 11(1), 122-134.

Vandeika, M., \& Longova, K., \& Olazs, D., \& Krcmar, M., \& Walker, S. (2016). Improved Maximum Strength, Vertical Jump and Sprint Performance after 8 Weeks of Jump Squat Training with Individualized Loads. Journal of Sport Science and Medicine, 15, 492-500.

Wall van der, E. E. (2014). Long-Distance Running: Running For A Long Life? Nederlands Health Journal, 22(3), 89-90.

Zhang, X. (2012). Research of Jumping Ability and Explosive Power Based on Plyometric Training. Informatics and Management Science III, 427-433. 